\section{Histone Deacetylase Inhibitors Up-regulate the Expression of Cell Surface MHC Class-I Molecules in B16/BL6 Cells}

\author{
Yasuhiko Komatsu* and Hideya Hayashi \\ Pharmaceuticals \& Biotechnology Laboratory, \\ Japan Energy Corporation, \\ 3-17-35, Niizo-Minami, Toda-shi, Saitama 335, Japan
}

(Received for publication September 26, 1997)

In a previous report, we showed that anthracyclines up-regulate the cell surface expression of MHC class-I molecules in B16/BL6 cells ${ }^{1)}$. By using the same assay system, we found an other type of MHC class-I upregulator in the culture broth of a newly isolated soil bacterium, Bacillus megaterium 6 N38. Here we report the isolation and characterization of this up-regulator, and its possible molecular mechanism.

Starting from 1 liter of culture supernatant of Bacillus megaterium $6 \mathrm{~N} 38$, the $\mathrm{MHC}$ class-I up-regulator was purified. After the $\mathrm{pH}$ of the supernatant had been adjusted to 13 with $\mathrm{NaOH}$, solvent extraction was performed with 1 liter of dichloromethane. The water fraction was adjusted to $\mathrm{pH} 2$ with $\mathrm{HCl}$, and extracted 3 times with $500 \mathrm{ml}$ of dicholoromethane each time. The organic fraction was condensed in vacuo to give $2.81 \mathrm{~g}$ of dark brown oil. The extract was applied onto a silica gel column (bed volume $=147 \mathrm{ml}$ ) equilibrated with dicholoromethane, and eluted with 1 liter of the same solvent. The eluate was collected and evaporated to give $1.97 \mathrm{~g}$ of a yellowish oil. The oil was applied to the second silica gel column (bed volume $=100 \mathrm{ml}$ ) equilibrated with cyclohexane, and then eluted stepwisely with $250 \mathrm{ml}$ of cyclohexane, $500 \mathrm{ml}$ of cyclohexane: dichloromethane $=8: 2$, and $700 \mathrm{ml}$ of cyclohexane: dichloromethane $=6: 4$. The last fraction was evaporated to give $880 \mathrm{mg}$ of pale yellowish oil. The sample was finally purified by reverse-phase HPLC using a TOSO HPLC system (SC-8010, UV-8010, CCMP) equipped with a semi-preparative column (Nacalai Tesque Cosmosil 5C18-AR, i.d. $=22 \mathrm{~mm}$, length $=25 \mathrm{~cm})$. The elution pattern was monitored by measuring the absorbance at $210 \mathrm{~nm}$. The elution condtions were as follows: solvent $\mathrm{A}, 0.1 \mathrm{M}$ sodium phosphate $(\mathrm{pH}=2)$; solvent $B$, equal mixture of $0.05 \mathrm{M}$ sodium phosphate $(\mathrm{pH}=2)$ and acetonitrile; linear gradient from $\mathrm{B}=0 \%$ to $100 \%$ over 100 minutes; flow rate, $5 \mathrm{ml} / \mathrm{minute}$. The active peak was collected, extracted by dichloromethane, and evaporated in vacuo to afford $20.1 \mathrm{mg}$ of a colorless oil (compound 1).

The molecular ion peak of 1 detected by FAB-MS was $101\left([\mathrm{M}-\mathrm{H}]^{-}\right.$ion $)$, indicating the molecular weight of 1 to be 102 . The ${ }^{1} \mathrm{H}$ and ${ }^{13} \mathrm{C}$ NMR spectra of 1 could be explained and assigned consistently, assuming compound 1 was isovaleric acid (data not shown). When the ${ }^{1} \mathrm{H}$ and ${ }^{13} \mathrm{C}$ NMR spectra of authentic isovaleric acid and those of compound 1 were compared, spectra of both were identical. These results taken together indicate compound $\mathbf{1}$ is isovaleric acid. In Fig. 1, the structures of isovaleric acid and related compounds are indicated.

Since $n$-butyric acid, a low-molecular-weight fatty acid structurally similar to isovaleric acid (Fig. 1), has been reported to induce cellular differentiation via histone hyperacetylation ${ }^{2)}$ caused by the inhibition of histone deacetylase, we examined whether isovaleric acid could hyperacetylate core histones in B16/BL6 cells. Histones isolated from B16/BL6 cells were treated with $15 \mathrm{~mm}$ $n$-butyric acid, $15 \mathrm{~mm}$ isovaleric acid, or $1 \mu \mathrm{m}$ trichostatin A for 6 hours, and analyzed by Acid-Urea-Triton gel electrophoresis. As shown in Fig. 2, isovaleric acid elicited histone hyperacetylation in B16/BL6 cells as did known inhibitors of histone deacetylase, $n$-butyric acid ${ }^{2)}$ and trichostatin $\mathrm{A}^{3 \text { ) }}$, suggesting that isovaleric acid also inhibits histone deacetylase.

Next, we examined whether histone deacetylase inhibitors would be able to induce the expression of $\mathrm{MHC}$ class-I molecules. As shown in Fig. 3 the potent and specific inhibitor of histone deacetylase, trichostatin $\mathrm{A}^{3)}$, stimulated the expression of MHC class-I molecules at concentrations markedly lower than those at which $n$-butyric acid or isovaleric acid was effective. These results strongly suggest that histone deacetylase inhibi-

Fig. 1. Structures of isovaleric acid and related compounds.
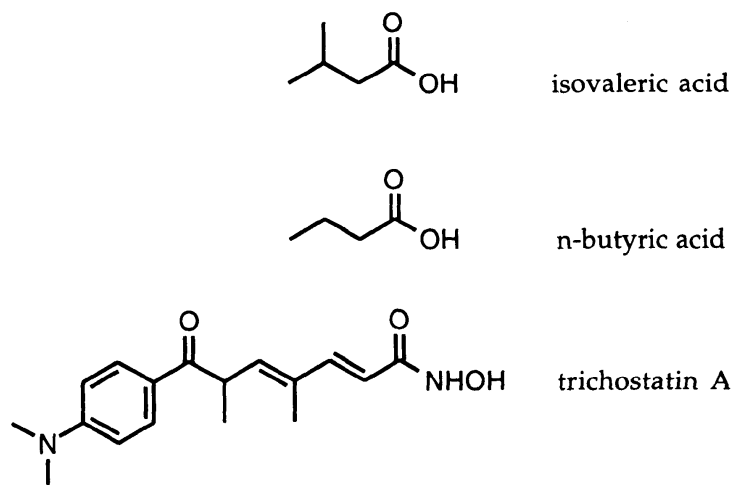
Fig. 2. Effects of $n$-butyric acid, isovaleric acid, and trichostatin $\mathrm{A}$ on histone acetylation in B16/BL6 cells.

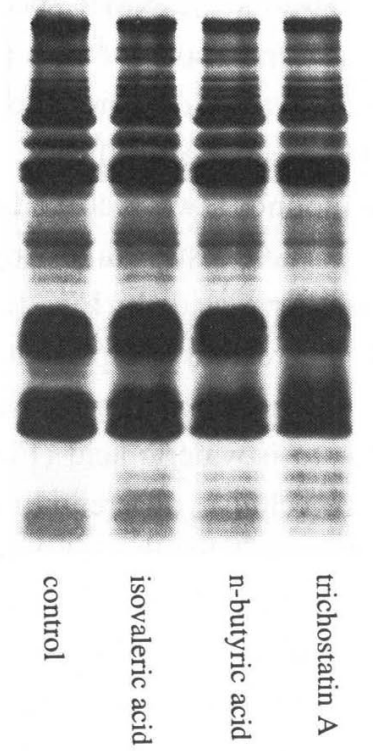

After incubation for 6 hours with or without $15 \mathrm{~mm}$ $n$-butyric acid, $15 \mathrm{~mm}$ isovaleric acid, or $1 \mu \mathrm{M}$ trichostatin A, histones of B16/BL6 cells were isolated and analyzed by Acid-Urea-Triton gel electrophoresis as described in "Experimental". The numbers beside the gel denote the positions of histone $\mathrm{H} 4$ acetylated by the indicated numbers of acetyl residues.

tion leads to the expression of MHC class-I molecule in B16/BL6.

Here we showed that variety of histone deacetylase inhibitors, including isovaleric acid, $n$-butyric acid ${ }^{2)}$, and trichostatin $\mathrm{A}^{3}$, induced $\mathrm{MHC}$ class-I expression in B16/BL6 cells. Trichostatin A did not induce the expression of MHC class-II and ICAM-1 molecules in the same cell line (data not shown), indicating there exists some specificity among cell surface molecules. Although recent reports suggest that histone deacetylase is important as a transcriptional corepressor ${ }^{4 \sim 10)}$, details of the control of histone acetylation-deacetylation and its link to specific gene expression remains to be elucidated. Since MHC class-I molecules present intracellular antigens after their processing to be recognized mainly by cytotoxic $\mathrm{T}$ cells ${ }^{11}$ ), if $\mathrm{MHC}$ class-I molecules are up-regulated on cancer cells or virus-infected cells, these cells may be recognized by the host defense system more easily, and thus be eliminated more efficiently. So it may be possible to use histone deacetylase inhibitors as immunotherapeutic drugs against cancer and viral
Fig. 3. Effects of isovaleric acid, $n$-butyric acid, and trichostatin $\mathrm{A}$ on the expression of $\mathrm{MHC}$ class-I molecules in B16/BL6 cells.

n-Butyric acid, $\bigcirc$ isovaleric acid, trichostatin A.

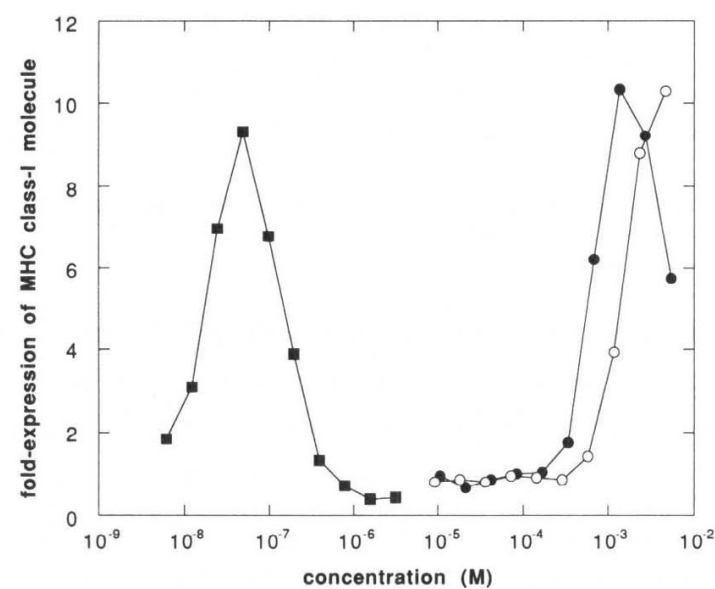

After B16/BL6 cells had been incubated for $72 \mathrm{~h}$ with various concentrations of n-butyric acid (closed circles), isovaleric acid (open circles), or trichostatin A (closed squares), the expression level of cellular MHC class-I molecules was determined by the cell ELISA method described in "Experimental". The data are expressed as relative values, assuming the level without any additive to be unity.

diseases

\section{Experimental}

Organisms and Cultivation

Bacillus megaterium 6N38 was isolated from soil collected in Noda-shi, Chiba, Japan, and its taxonomic identification was performed by NCIMB (The National Collection of Industrial and Marine Bacteria Limited, Scotland, UK). This strain has been deposited in the Fermentation Research Institute of The Agency of Industrial Science \& Technology, Japan (accession number: FERM BP-3760). The bacteria were grown in a fermentation medium containing (/liter) $\mathrm{Na}_{2} \mathrm{HPO}_{4}, 6 \mathrm{~g}$; $\mathrm{KH}_{2} \mathrm{PO}_{4}, 3 \mathrm{~g} ; \mathrm{NaCl}, 0.5 \mathrm{~g} ; \mathrm{NH}_{4} \mathrm{Cl}, 1 \mathrm{~g} ; \mathrm{MgSO}_{4}, 2$ mmole; glucose, $4 \mathrm{~g} ; \mathrm{CaCl}_{2}, 0.1$ mmole; casamino acid, $5 \mathrm{~g}$; peptone, $40 \mathrm{~g}$; and yeast extract, $5 \mathrm{~g}$. The culture was agitated in a reciprocal shaker $(135 \mathrm{rpm})$ for 48 hours at $45^{\circ} \mathrm{C}$. The culture broth was centrifuged, and the supernatant (1 liter) was used as a starting material for the purification of MHC class-I up-regulator.

The established mouse melanoma line B16/BL6 was obtained from the National Cancer Institute, USA. The cells were grown in modified EAGLE's medium supple- 
mented with $10 \%$ fetal calf serum (Irvine Scientific, California, USA) at $37^{\circ} \mathrm{C}$ in a $5 \% \mathrm{CO}_{2}$ humidified atmosphere.

Measurement of MHC Class-I Molecule Up-regulating Activity

The expression of MHC class-I molecules on the surface of B16/BL6 cells was determined as reported previously by an enzyme-linked immunosorbent assay $\left(\right.$ ELISA) ${ }^{1}$.

Acid-Urea-Triton (AUT) Gel Electrophoresis for Determining Histone Hyperacetylation

Cellular histones were extracted as reported previous$1 y^{3)}$. Hyperacetylation of core histone of B16/BL6 cells was determined by the Acid-Urea-Triton gel electrophoresis technique, originally reported by COHEN et al. ${ }^{12)}$ and modified by Yoshida et al. ${ }^{3)}$ with further small modification, in which gels were stained with silver instead of Coomassie Brilliant Blue.

Physico-chemical Data

FAB-MS spectrum was obtained with a Finnigan MAT TSQ7000 triple quadrupole mass spectrometer. NMR spectra were recorded on JEOL GSX-270 NMR Spectrometer with ${ }^{1} \mathrm{H}$ NMR at $270.05 \mathrm{MHz}$ and ${ }^{13} \mathrm{C}$ NMR at $67.80 \mathrm{MHz}$.

\section{Acknowledgment}

We would like to thank Dr. Minoru Yoshida, University of Tokyo, for helpful discussion; HISASHI SAEKI for culturing B. megaterium $6 \mathrm{~N} 38$. We also thank Hirotada TAKAHASHI, NaOmi Tanabe, Setsu Matsumoto, and Atsuko Noda for their excellent technical assistance. NMR and MS spectral analyses were performed by the Japan Energy Analytical Research Center Co., Ltd.

\section{References}

1) Komatsu, Y.; O. TaKahashi \& H. Hayashi: Identification of the anthracycline antibiotic 4- $O-(\beta$-D-glucopyr- anuronosyl)- $\varepsilon$-rhodomycinone, produced by Streptomyces ruber JCM3131, as an up-regulator of MHC class-I molecules in B16/BL6 cells. J. Antibiotics 51: 85 88, 1998

2) Sealy, L. \& R. Chalkley: The effect of sodium butyrate on histone modification. Cell 14: 115 121, 1978

3) Yoshida, M.; M. Kijima, M. Akita \& T. Beppu: Potent and specific inhibition of mammalian histone deacetylase both in vivo and in vitro by trichostatin A. J. Biol. Chem. 28: $17174 \sim 17179,1990$

4) Heinzel, T.; R. M. Lavinsky, T. M. Mullen, M. Soderstrom, C. D. Laherty, J. Torchia, W. M. Yang, G. Brard, S. D. Ngo, J. R. Davie, E. Seto, R. N. Eisenman, D. W. Rose, C. K. Glass \& M. G. Rosenfeld: A complex containing $\mathrm{N}-\mathrm{CoR}, \mathrm{mSin} 3$ and histone deacetylase mediates transcriptional repression. Nature 387: $43 \sim 48,1997$

5) Alland, L.; R. Muhle, H. Hou Jr., J. Potes, L. Chin, N. Schreiber-Agus \& R. A. DePinho: Role of N-CoR and histone deacetylase in Sin3-mediated transcriptional repression. Nature 387: 49 55, 1997

6) Hassig, C. A.; T. C. Fleischer, A. N. Billin, S. L. SCHREIBER \& D. E. AYER: Histone deacetylase activity is required for full transcriptional repression by $\mathrm{mSin} 3 \mathrm{~A}$. Cell 89: 341 347, 1997

7) Laherty, C. D.; W. M. Yang, J. M. Sun, J. R. Davie, E. Seto \& R. N. Eisenman: Histone deacetylases associated with the $\mathrm{mSin} 3$ corepressor mediate $\mathrm{Mad}$ transcriptional repression. Cell 89: 349 356, 1997

8) Zang, Y.; R. Iratni, H. Erdjument-Bromage, P. Tempst \& D. ReINBERG: Histone deacetylases and SAP8, a novel polypeptide, are components of a human $\operatorname{Sin} 3$ complex. Cell 89: $357 \sim 364,1997$

9) Hadosh, D. \& K. Struhl: Repression by Ume6 involves recruitment of a complex containing $\operatorname{Sin} 3$ corepressor and Rpd3 histone deacetylase to target promoters. Cell 89: $365 \sim 371,1997$

10) Nagy, L.; H. Y. Kao, D. Chakravarti, R. J. Lin, C. A. Hassig, D. E. Ayer, S. L. Screiber \& R. M. Evans: Nuclear receptor repression mediated by a complex containing SMRT, mSin3A, and histone deacetylase. Cell 89: $373 \sim 380,1997$

11) Braciale, T. J.: Antigen processing for presentation by MHC class I molecules. Curr. Opin. Immunol. 4: 59 62, 1992

12) Cohen, L. H.; K. M. Newcock \& A. Zweidler: Stagespecific switches in histone synthesis during embryogenesis of the sea urchin. Science 190: 994 997, 1975 